\title{
Fibromyalgia in Women with Acne Vulgaris
}

\author{
Abdulsatar J Mathkhor ${ }^{1 *}$ and Jinan Q Mohammed ${ }^{2}$ \\ ${ }^{1}$ Department of Rheumatologist, Rheumatology unit in Basrah Teaching Hospital Basrah, Iraq \\ ${ }^{2}$ Department of Dermatologist, Dermatology unit in Basrah Teaching Hospital Basrah, Iraq
}

Submission: September 30, 2020; Published: October 06, 2020

*Corresponding author: Abdulsatar J Mathkhor, Department of Rheumatologist, Rheumatology unit in Basrah Teaching Hospital Basrah, Iraq

\begin{abstract}
Abstarct
Background: Widespread pain and fibromyalgia syndrome (FMS) are observed in many patients with autoimmune and inflammatory disorders.

Aim: The aim of this study was to investigate the prevalence of fibromyalgia and its associated symptoms in women with acne vulgaris.

Patients and methods: sixty women with acne vulgaris and 45 age matched controls were enrolled for the study, the mean age and disease duration of the patient group were $21.75 \pm 2.1$ and $6.5 .0 \pm 1.5$ years respectively, and the mean age of the controls was $21.3 \pm 2.8$ years. Women with acne vulgaris was evaluated by using the Global Acne Scale. A two stage classification process was applied to determine the presence of FMS in women with acne vulgaris and controls. Stage 1 was answering the diffuse widespread pain questionnaire. In Stage 2, all patients with wide spread pain were examined for 18 tender points.
\end{abstract}

Results: A total of $30(50.0 \%)$ women with acne vulgaris were found to have widespread pain. A total of 18 women met the criteria of FMS with a prevalence rate of $30.0 \%$.

Conclusion: FMS and its associated symptoms are more prevalent in women with acne vulgaris than those in the general population. FMS was found to be associated with the severity of acne, and overweight. Proper management that decrease the severity of acne, and body weight may be associated with the alleviation of FMS symptoms in patient with acne vulgaris.

Keywords: Skin; Widespread pain; Fibromyalgia associated symptoms; Acne vulgaris; Global acne score; Autoimmune; Rheumatic diseases; menstrual irregularity

\section{Introduction}

Skin is the human body's main interface with the external environment; the skin is considered as the body's major public relations tool [1]. Therefore, any condition which affects the skin may, affect the ability of an individual to function properly in society [2], highly due to the negative psychological impact of the disease than the disease itself [1], one of these skin conditions, is acne vulgaris. Acne vulgaris is defined as a common cutaneous inflammatory disorder affecting around $9.4 \%$ of the global population and $85 \%$ of adolescents worldwide [3,4]. Its onset usually starts with the period of the secondary sexual characteristics development and may contributes to the emotional and psychological challenges encountered at this period [5]. The pathogenesis of acne vulgaris is multifactorial, in addition to the genetic predisposition, bacterial infections, hormonal disorders, sun exposure, smoking, and diet; stress play a crucial role in the pathogenesis of acne vulgaris [6].
Fibromyalgia syndrome (FMS) is a chronic diffuse widespread pain condition associated with other symptoms including morning stiffness, anxiety, fatigue, sleep disturbance, and cognitive problems $[7,8]$. The exact pathophysiologic mechanism of fibromyalgia is not well known, it may result from, or coexist with neurohormonal or immunologic disorders, genetic predisposition, infections, rheumatic diseases, physical trauma or psychological illness [9]. The possible mechanisms of the etiopathogenesis between acne and FMS, may be stress-related, and the severity of symptoms in both acne and FMS is affected by stress. Stress can modulate different adhesion molecules [10], there is a significant reduction in L-selectin and b2-integrin expression on the surface of polymorphonuclear leukocytes in patients with FMS [10]. These adhesion molecules play a crucial role in the destruction of infectious agents and removing toxic substances from the body. Since bacterial infection plays an important role in the development 
of acne, a reduction in the adhesion molecules may be a common underlying pathway in the pathogenesis of both FMS and acne [10]. Stress may affect acne in different possible mechanisms, such as the secretion of inflammatory cytokines, hormones, and different neurotransmitters. Substance $\mathrm{P}$, which is neuropeptide related to the stress and pain, found to be upregulated in the skin of acne patients [11]. Therefore, substance P may have an important role in the pathogenesis of both acne vulgaris and FMS [12]. FMS can associate with other rheumatologic and inflammatory disorders, like rheumatoid arthritis, systemic lupus erythematosus, psoriatic arthritis, Sjogren syndrome, and skin disorder like, psoriasis [1317]. Some of fibromyalgia associated clinical symptoms have been addressed in patients with acne vulgaris in the literatures $[18,19]$. However, to our knowledge, there is only one study evaluating the frequency of FMS in patients with acne vulgaris [20]. We therefore conducted this study was to determine the prevalence of fibromyalgia and its associated clinical symptoms in patients with acne vulgaris.

\section{Patients and Methods}

This was a cross-sectional study carried out in the outpatient departments of Dermatology and Rheumatology in Basrah Teaching Hospital from January 2019 to February 2020. A sample of 60 women with acne vulgaris, diagnosed by a dermatologist in the dermatology outpatient, and 45 age matched controls recruited from the general population were enrolled for this study. The exclusion criteria were inflammatory, autoimmune, rheumatic diseases, infection, congenital adrenal hyperplasia, polycystic ovarian syndrome, diabetes mellitus, pregnancy, thyroid disorders, psychiatric disorders, and history of cancer. All participants were questioned about age, disease duration, widespread pain, and any disturbance in the menstrual cycle. Acne vulgaris was evaluated by using the Global Acne Scale [1]. This scoring scale is used to determine the severity of the acne by evaluating the types of acne lesions (no lesions $=0$, comedones $=1$, papules $=2$, pustules $=3$, and nodules $=4$ ) and their anatomic locations (forehead $=2$, right cheek $=2$, left cheek $=2$, nose $=1$, chin $=1$, chest and upper back= $3)$. The local score is determined by multiplying the anatomic location score by the grade (0-4), and the global score is the sum of the local scores. The Global Acne Scale score ranges from 0 (no acne), 1-18 (mild acne), 19-30 (moderate acne), 31-38 (severe acne), and $>39$ (very severe acne) [1]. A diagnosis of FMS was confirmed according to the two-stage classification process that was proposed by the 1990 ACR classification criteria for FMS (7). Stage 1 was composed of the patients answering the diffuse widespread pain questionnaire. Stage 2 comprised evaluation of all patients and controls complaining of diffuse pain; this evaluation included the assessment of 18 tender points and 4 control nontender points through digital palpation with an approximate force of $4 \mathrm{~kg}$ (the amount of pressure required to blanch a nail). The four control non-tender points are: the middle of the forehead, the volar aspect of the mid forearm, the thumb nail, and the muscles of the anterior thigh. To meet the diagnostic criteria, musculoskeletal pain had to have been present for at least 3 months, and pain must have been present in 11 or more out of 18 specific tender points on digital palpation. All participants were evaluated by a rheumatologist, by answering questionnaires about the following FMS associated symptoms: morning stiffness, sleep disturbance, fatigue, headache, anxiety, and irritable bowel

\section{Ethical Considerations}

The study was conducted in accordance with the principles of the Declaration of Helsinki, and verbal consent was obtained from all participants prior to their involvement.

\section{Statistical Analysis}

SPSS Software version 25.0 was used for data analysis. Percentages and mean was used to present the data in tables. Comparison of study groups was carried out using chi-square and Fisher's exact test for categorical data, and Student's t-test for continuous data. P-value of $<0.05$ was considered statistically significant.

\section{Result}

Table 1 shows the demographic distributions of both patients and control groups. There were 60 women with acne vulgaris with mean age and disease duration of $21.75 \pm 2.1$ and $6.5 .0 \pm 1.5$ years respectively. There were 30 (50.0\%) women with widespread pain compared with 3 (6.6\%) women with widespread pain in the control group which is a statistically significant difference $(\mathrm{P}<0.05)$ as shown in Table 2. There were 18 (30.0\%) women fulfilled the 1990 ACR criteria for classification of FMS in the patients group, compared to $1(2.2 \%)$ woman in the control group, difference is also statistically significant $(\mathrm{P}<0.05)$. Table 3 shows the frequency of clinical, and FMS associated features in women with acne vulgaris and in the controls, FMS associated features, with the exception of morning stiffness were all more frequent in patient group than in controls in a statistically significant difference (all $\mathrm{P}<0.05$ ). Menstrual disturbances were more frequent in patients group than in the controls and the difference is statistically significant $(\mathrm{P}<0.05)$. Global acne score was $35 \pm 2.3$ in women with FMS, whereas it was $22.1 \pm 3.3$ in acne women without FMS. Body mass index was $30 \pm 1.8$ in women with FMS, whereas it was 20.5 \pm 1.3 in acne women without FMS.

Table 1: The demographic data of both women with acne vulgaris and controls.

\begin{tabular}{|c|c|c|c|}
\hline Characteristics & Acne Vulgaris & Controls & P Value \\
\hline Total No. (\%) & $60(100 \%)$ & $45(100 \%)$ & \\
\hline Age & $21.75 \pm 2.1$ & $21.3 \pm 2.8$ & $>0.05$ \\
\hline Disease duration & $6.5 \pm 1.5$ & & \\
\hline
\end{tabular}


Table 2: Frequency of FMS in women with acne vulgaris vs. controls.

\begin{tabular}{|c|c|c|c|}
\hline & Acne vulgaris & Controls & 45 \\
\hline Total No. & 60 & $3(6.6 \%)$ & $<0.05$ \\
\hline Widespread pain & $30(50.0 \%)$ & $1(2.2 \%)$ & $<0.05$ \\
\hline FMS & $18(30.0 \%)$ & & \\
\hline
\end{tabular}

Table 3: The distribution of FMS associated, and clinical features in women with acne vulgaris and controls.

\begin{tabular}{|c|c|c|c|}
\hline Characteristics & Acne Vulgaris & Controls & P Value \\
\hline Total (\%) & $60(100 \%)$ & $45(100 \%)$ & \\
\hline Morning stiffness & $4(6.6 \%)$ & $1(2.2 \%)$ & $>0.05$ \\
\hline Sleep disturbance & $29(48.3 \%)$ & $2(4.5 \%)$ & $<0.05$ \\
\hline Anxiety & $28(46.6 \%)$ & $2(4.5 \%)$ & $<0.05$ \\
\hline Depression & $26(43.3 \%)$ & $2(4.5 \%)$ & $<0.05$ \\
\hline Fatigue & $26(43.3 \%)$ & $1(2.2 \%)$ & $<0.05$ \\
\hline Irritable bowel & $25(41.6 \%)$ & $1(2.2 \%)$ & $<0.05$ \\
\hline Menstrual disturbances & $30(50.0 \%)$ & $3(6.6 \%)$ & $<0.05$ \\
\hline \multicolumn{4}{|l|}{ Global Acne Scale in (mean) } \\
\hline Patients with FMS & $35.0 \pm 2.3$ (severe) & & \multirow{2}{*}{$<0.001$} \\
\hline Patients without FMS & $22.1 \pm 3.3$ (moderate) & & \\
\hline \multicolumn{4}{|l|}{ Body Mass Index } \\
\hline Patients with FMS & $\begin{array}{c}30.0 \pm 1.8 \\
\text { ( overweight) }\end{array}$ & & \multirow{2}{*}{$<0.001$} \\
\hline Patients without FMS & $\begin{array}{c}20.5 \pm 1.3 \\
\text { (normal weight) }\end{array}$ & & \\
\hline
\end{tabular}

\section{Discussion}

In this study, widespread pain was found to be more prevalent in women with acne vulgaris than in the control group in a prevalence rate of $50.0 \%$ and $6.6 \%$ respectively. The prevalence rate of FMS among women with acne vulgaris was found to be $30.0 \%$ which is higher when compared to a study done by Yazmalar et al. [20] who found FMS was affected $16 \%$ of women in his study group, and another study done by Thune [17] who found FMS was affected $13 \%$ of women with psoriasis which is another distressing skin disease, and it seems to be low when compared to a study done by Torresani et al. [21] who found the prevalence rate of FMS was $53.9 \%$ in women with chronic urticaria. The prevalence rate of FMS in our study population is considered high when compared to the prevalence rate in the control group and in women in the general population [22]. Therefore, FMS is more prevalent in women with acne vulgaris than in the general population. The increase risk of developing FMS among acne vulgaris patients may be attributed to the common underlying pathway in the pathogenesis of both FMS and acne [10]. Sleep disturbance, anxiety, depression, and fatigue were the most common non-musculoskeletal manifestations recorded in patients with acne vulgaris in this study. In contrast to Misery et al finding [18], we found that sleep disturbance was more common in acne vulgaris women than in healthy controls. Previous studies have reported that patients with acne vulgaris have increased frequency of anxiety [23,24], we also recorded a comparable finding in our study. Depression was more frequent among our study group, finding is comparable to other studies $[25,26]$, but it is not in agreement with some other studies $[24,27]$. Fatigue was more frequent among our study group patients than in the controls, this finding is in contrast to a study done by Yazmalar et al. [20] who found no difference in the frequency of fatigue between the acne patients and healthy controls.

Many women experience a worsening of acne during the premenstrual cycle [28]. We found that menstrual cycle disturbance was more common in women with acne vulgaris than in healthy controls, this finding is in agreement with Yazmalar et al. [20], Finding Premenstrual exacerbation of acne is multifactorial [29]. Higher levels of androgens and oestrogens during the follicular phase and periovulation causes increased sebum production, higher level of skin lipids, and subsequent increase in skin microflora resulting in acne exacerbation. Combined oestrogen/ progesterone contraceptives cause improvement in acne by 
decreasing the amount of free, biologically active androgens [30]. In our study FMS was more frequent in women with severe acne than those with moderate one, result not in agreement with Law et al. [31] Finding who recorded that the clinical severity of acne did not correlate strongly with the effect on the quality of life (QoL), and the QoL of adolescents is not only determined by acne severity. The relationship between obesity and fibromyalgia has been addressed in literature [32], in our study, FMS was more frequent in overweight acne women than those with normal weight. It is reported that; successful weight management changes the expression of FMS [32].

\section{Conclusion}

FMS and its associated symptoms are more prevalent in women with acne vulgaris than women in the general population. FMS was found to be associated with the severity of acne, and overweight. Proper management that decrease the severity of acne, and body weight may be associated with the alleviation of FMS symptoms in women with acne vulgaris.

\section{Acknowledgment}

We kindly appreciate the role all participants in the study.

\section{References}

1. Ogedegbe EE, Henshaw EB (2012) Severity and impact of acne vulgaris on the quality of life of adolescents in Nigeria. Clin Cosmet Investig Dermatol 7: 329-334.

2. Ayer J, Burrows N (2006) Acne: More than skin deep. Postgrad Med J 82(970): 500-506.

3. Stollery N (2013) Sebaceous and sweat gland disorders. Practitioner 257(1757):32-33

4. Tan JKL, Bhate K (2015) A global perspective on the epidemiology of acne. Br J Dermatol 172(S1): 3-12.

5. Misery L (2011) Consequences of psychological distress in adolescents with acne. J Invest Dermatol 131(2): 290-292.

6. Albuquerque RGR, Rocha MAD, Bagatin E, Tufik S, Andersen ML (2014) Could adult female acne be associated with modern life? Arch Dermatol Res 306(8): 683-688.

7. Wolfe F, Clauw DJ, Fitzcharles MA, Goldenberg DL, Katz RS, et al. (2010) The American College of Rheumatology preliminary diagnostic criteria for fibromyalgia and measurement of symptom severity. Arthritis Care Res 62(5): 600-610.

8. Wolfe F, Clauw DJ, Fitzcharles MA, Goldenberg DL, Häuser W, et al (2016) Revisions to the $2010 / 2011$ fibromyalgia diagnostic criteria. Semin Arthritis Rheum 46(3): 319-329.

9. Buskila D, Atzeni F, Sarzi-Puttini P (2008) Etiology of fibromyalgia: The possible role of infection and vaccination. Autoimmun Rev 8(1): 41-43.

10. Kaufmann I, Schelling G, Eisner C, Richter HP, Beyer A, et al. (2009) Decrease in adhesion molecules on polymorphonuclear leukocytes of patients with fibromyalgia. Rheumatol Int. 29(9): 1109-1111.

11. Toyoda M, Nakamura M, Makino T, Kagoura M, Morohashi M, et al. (2002) Sebaceous glands in acne patients express high levels of neutral endopeptidase. Exp Dermatol 11(3): 241-247.

12. Clauw DJ (2014) Fibromyalgia: A clinical review. JAMA 311(15): 15471555.
13. Wolfe F, Cathey MA, Kleinheksel SM (1984) Fibrositis (Fibromyalgia) in rheumatoid arthritis. J Rheumatol 11(6): 814-818.

14. Middleton GD, Mcfarlin JE, Lipsky PE (1994) The prevalence and clinical impact of ibromyalgia in systemic lupus erythematosus. Arthritis Rheum 37(8): 1181-1188.

15. Magrey MN, Antonelli M, James N, Khan MA (2013) High Frequency of Fibromyalgia in Patients with Psoriatic Arthritis: A Pilot Study. In: Lisse JR (ed), pp.762921.

16. Vitali C, Tavoni A, Neri R, Castrogiovanni P, Pasero G, et al. (1989) Fibromyalgia features in patients with primary sjögren's syndrome: Evidence of a relationship with psychological depression. Scand J Rheumatol 18(1): 21-27.

17. Thune PO (2005) The prevalence of fibromyalgia among patients with psoriasis. Acta Derm Venereol 85(1): 33-37.

18. Misery L, Wolkenstein P, Amici JM, Maghia R, Brenaut E, et al. (2015) Consequences of acne on stress, fatigue, sleep disorders and sexual activity: A population- based study. Acta Derm Venereol 95(4): 485-488.

19. Silverberg JI, Silverberg NB (2014) Epidemiology and extracutaneous comorbidities of severe acne in adolescence: A U.S. population-based study. Br J Dermatol 170(5): 1136-1142.

20. Yazmalar L, Çelepkolu T, Batmaz İ, Sariyildiz MA, Sula B, Alpayci M, et al (2016) High frequency of fibromyalgia in patients with acne vulgaris. Arch Rheumatol 31(2):170-175.

21. Torresani C, Bellafiore S, De Panfilis G (2009) Chronic urticaria is usually associated with fibromyalgia syndrome. Acta Derm Venereol 89(4): 389-392.

22. Wolfe F, Ross K, Anderson J, Russell IJ, Hebert L, et al. (1995) The prevalence and characteristics of fibromyalgia in the general population. Arthritis Rheum 38(1):19-28.

23. Grahame V, Dick DC, Morton CM, Watkins O, Power KG, et al. (2002) The psychological correlates of treatment efficacy in acne. Dermatology Psychosom 3(3):119-125.

24. Golchai J, Khani SH, Heidarzadeh A, Eshkevari SS, Alizade N, et al. (2010) Comparison of anxiety and depression in patients with acne vulgaris and healthy individuals. Indian J Dermatol 55(4): 352-354.

25. AlHuzali S, AlMalki K, AlNikhali S, AlMatrafi K (2014) Prevalence of depression among acne patients in King Faisal Hospital and King Abulaziz Hospital in Makkah, Saudi Arabia. Int J Med Sci Public Heal 3(10): 1.

26. Öztürk A, Deveci E, Bağcioğlu E, Atalay F, Serdar Z, et al. (2013) Anxiety, depression, social phobia, and quality of life in Turkish patients with acne and their relationships with the severity of acne. Turkish J Med Sci 43(4): 660-666.

27. Duman H, Topal IO, Kocaturk E, Duman MA (2016) Evaluation of anxiety, depression, and quality of life in patients with acne vulgaris, and quality of life in their families. Dermatologica Sin 34(1): 6-9.

28. Dréno B, Layton A, Zouboulis CC, López-Estebaranz JL, Zalewska-Janowska A, et al (2013) Adult female acne: A new paradigm. J Eur Acad Dermatology Venereol 27(9): 1063-1070.

29. Steventon K (2011) Expert opinion and review article: The timing of comedone extraction in the treatment of premenstrual acne-a proposed therapeutic approach. Int J Cosmet Sci 33(2): 99-104.

30. Carey MS, Allen RH (2012) Non-contraceptive uses and bene fits of combined oral contraception. TOG 14(4): 223-228.

31. Law MPM, Chuh AAT, Lee A, Molinari N (2010) Acne prevalence and beyond: Acne disability and its predictive factors among Chinese late adolescents in Hong Kong. Clin Exp Dermatol 35(1): 16-21.

32. Öztekin Long, Nicole M, Badre D (2008) Genetic changes NIH Public Access. Bone 23(1): 1-7. 
CC This work is licensed under Creative (C) Commons Attribution 4.0 License BY DOI: 10.19080/JGWH.2020.20.556027
Your next submission with Juniper Publishers will reach you the below assets

- Quality Editorial service

- Swift Peer Review

- Reprints availability

- E-prints Service

- Manuscript Podcast for convenient understanding

- Global attainment for your research

- Manuscript accessibility in different formats

( Pdf, E-pub, Full Tsext, Audio)

- Unceasing customer service

Track the below URL for one-step submission https://juniperpublishers.com/online-submission.php 